\title{
Mineral resource management: Evaluating mineral resource throughput management
}

\author{
J.O. Claassen ${ }^{a *}$ and P.G. Laurens ${ }^{b}$ \\ ${ }^{a}$ Geology Department, University of the Free State, P O Box 339, Bloemfontein, 9300, South Africa \\ ${ }^{\mathrm{b}}$ Exxpleo (Pty) Ltd, Pretoria, South Africa \\ *To whom all correspondence should be addressed \\ joclaass@gmail.com
}

\begin{abstract}
Mining operations are increasingly challenged to sustain and improve its profitability. Mineral Resource Throughput Management (MRTM) is showing immense promise to become a fit for use mining management and improvement methodology. Research indicated that the three dimensions of MRTM, namely physical and non-physical constraint management, product payability improvement and optimised decision-making are largely based on the theory of mechanistic and organic systems, the theory of constraints and chaos theory. It also enhances best practices in quality and mining operations management. Managing the impact of variable geology (variable ore and ore body morphology), mining (variable and changing process flow chains) and beneficiation (material compatibility) conditions as well as external variables on production within the MRTM context, mainly centres around understanding and predicting the correct flow behaviour of ore (physical and quality) in downstream processes and synchronisation of the total mining value chain.
\end{abstract}

\section{Introduction}

In many countries the mining, minerals and metals industry has been in a decline for more than a decade (Miningfeeds, 2012). Reasons given for this decline include changes in geological complexity (associated with declining ore grades), the legislative environment and productivity. These and other changes mentioned in literature resulted in an overall increase in the complexity of the mining environment. With most mining operations characterised by a high level of complexity, a need exists to employ a fit for use mining management and improvement approach that supports adaptability and flexibility as explained in the contingency theory (Donaldson, 2001).Today, most mining organisations are characterised by a mechanistic design and approach towards its environment. It has been indicated (Burns \& Stalker, 1961; Courtright, Fairhurst \& Rogers, 1989; Scott, 2002) that a mechanistic approach supports simple and stable tasks and systems. An organic or systemic design and approach on the other hand is suitable for complex and uncertain environments and supports flexibility as well as adaptability.

Donaldson (2001) suggested that organisations will be more successful if its design and approach to the business supports its primary goal. From this perspective, it can be argued that most mining organisations probably employ a less desirable organisational design and management approach. In relatively simple and stable mining environments some concepts which support a systemic approach to mining such as "Mine to Mill" and "Pit to Port" (Mine to Mill, 1998) have been adopted by some mining operators. These approaches are mainly based on the theory of constraints (TOC) developed by Goldratt (1984). Other management and improvement methodologies implemented by the mining industry, with varying success, include total quality management (TQM) (Dahlgaard and Dahlgaard-Park, 2006), business process management (BPM) (Vom Brocke and Rosemann, 2010) and Six Sigma (SS) (Eckes, 2001).

A number of fundamental shortcomings in these methodologies make it less effective when employed in mining. A major stumbling block in the application of these methodologies in mining is its handling of variable raw material quality. In mining, all raw material/ore within the reserve boundaries is processed whereas in manufacturing and simple production systems poor quality material is either rejected as part of the quality management process or diluted with good quality material (averaging of quality is a typical mechanistic approach to quality control) to such an extent that its impact on downstream processing performance is negligible. This blending or dilution approach poses a serious problem in mining as the poor quality material may in fact control the downstream processing/flow behaviour of the blends. Here, the poor quality material possibly induces nonlinear or 'antagonistic' effects (CMR UCT, 2013), which weigh the flow behaviour of the blend towards that of the poor quality material. Furthermore, variable raw material quality and ever-changing mining production lines result in moving bottlenecks/constraints in many mining operations. These two phenomena are encountered on a daily basis in mining operations and can severely impact performance. It should be noted that mining exhibits a number of unique features when compared with manufacturing that should be taken into account from an operations management perspective. These include variable geology (mineralogical, structural and geometrical), moving mining processing chains (equipment moves to raw material and it changes from day to day as a result of mine development and production scheduling), varying plant feed qualities and moving 
bottlenecks (mainly a result of varying feed qualities). This variability typically causes instability in mining systems which in turn leads to under-performing operations.

The Mineral Resource Throughput Management (MRTM) methodology, developed in the mining industry over more than 30 years and taught at the UFS's Geology Department as a Masters Programme since 2001, is evaluated as a fit for use mining operations management and improvement methodology by investigating the underlying theory of MRTM and comparing MRTM (logic and practices) with typical operations management (OM) and other broad-based OM practices (TQM, TOC and SS).

\section{Underlying theory of MRTM}

Burns and Stalker (1961) published the Theory of Mechanistic and Organic Systems which describes organisational designs for simple, stable environments as mechanistic and designs suitable for complex, changing environments as organic structures. It was argued that these structures support management's will to gain power, domination and control over the natural environment and labour. Therefore, these structures could be viewed as products of two different approaches (mindset and behaviour) to enterprises operating in a continuum between simple, stable environments and complex, changing environments. The mindset and behaviours, however, not only affect organisational design but the entire business environment, i.e. the way in which people think about and behave towards finances, maintenance, production, quality control, continuous improvement, etc.

As far as MRTM is concerned, it not only recognises the fact that a fit for use organisational structure should be employed to support a specific organisation, but also that the two approaches (mechanistic and systemic) can often yield significantly different outcomes when applied to the same problem and/or in the same environment. Furthermore, the three MRTM dimensions (refer to Figure 1) recognise that a systemic approach towards the exploitation of complex mineral resources and the management of mining organisations yield superior results compared to when a mechanistic approach is employed.

Therefore, the MRTM methodology is first and foremost based on systemic thinking logic and behaviour (theory of mechanistic and systemic systems). However, within the MRTM environment mechanistic metaphors are often employed to describe or define the organic/systemic side of the continuum. MRTM is also seen as a flow-based methodology. All three dimensions of MRTM, namely the physical flow, the product payability (monetary value of the product influenced by product volume, quality and consistency in quality) and the logical decision-making dimension contain elements of the Theory of Constraints (systemic approach) as shown in Figure 1.

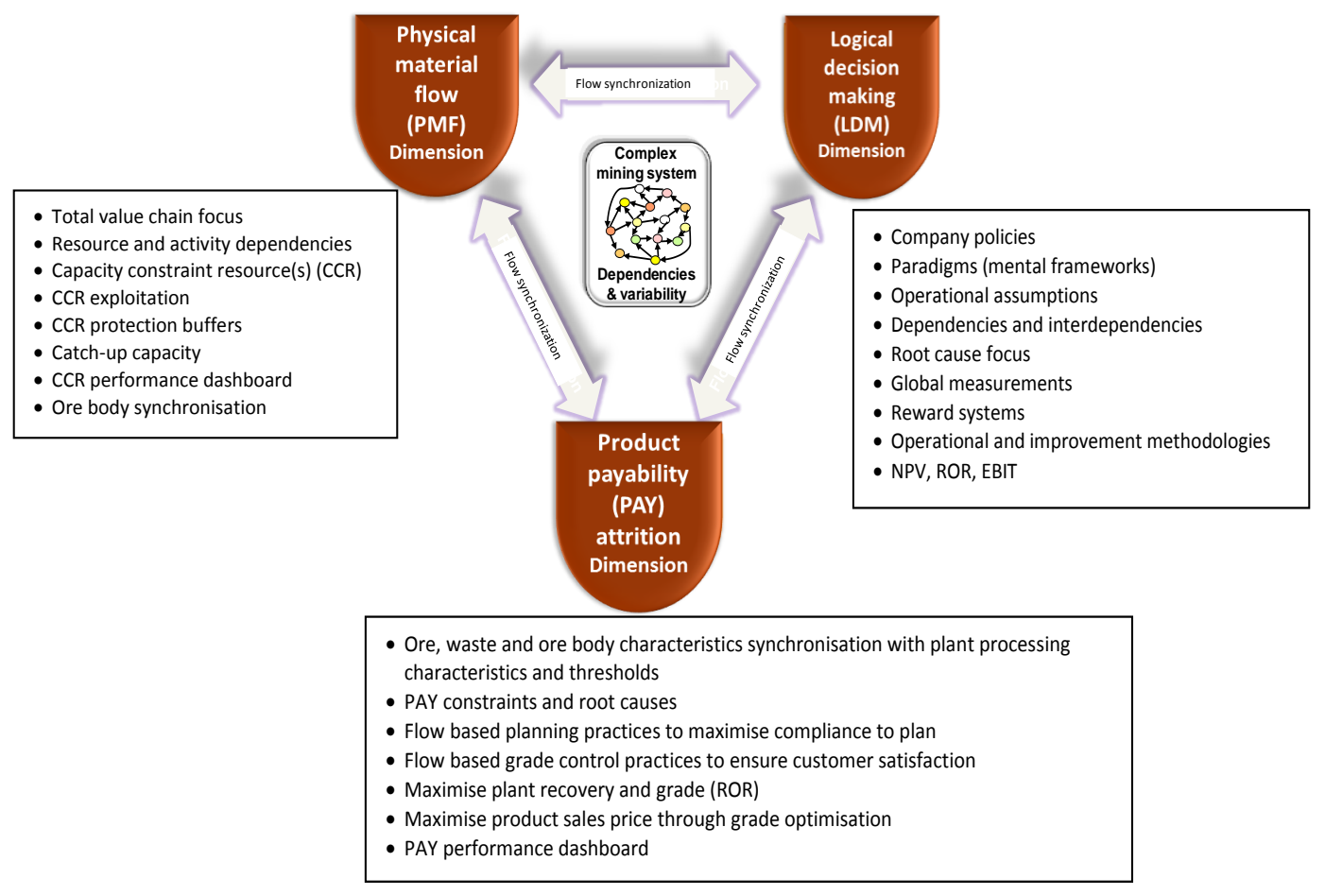

Figure 1: Illustration of the three dimensions of MRTM

The application of TOC in complex mining environments is, however, limited due to several shortcomings in the theory and its application as alluded to earlier. The first major shortcoming of the TOC, as far as mining operations management is concerned, is its handling of variable raw material quality. In fact, it might be argued that TOC assumes that raw material quality non-conformances are adequately dealt with before the material enters the processing chain. 
This is not the case in most complex mining operations where the inherent variability in the geology of the reserve dictates throughput and downstream processing effectiveness. Secondly, the application of the five focusing steps of TOC and the DBR scheduling practice rely on the premise that the constraint(s) will retain its position in the value chain long enough so that it can be exploited, subordination of all other steps and activities can take place and possibly even be elevated to the next performance level. If the constraint frequently moves even though the physical and non-physical flow environment have been synchronised and buffered, as is the case in complex mining environments, then the application of TOC's management and improvement principles and techniques could be limited, i.e. limited benefits in terms of effectively stabilising complex mining environments.

Furthermore, cause-and-effect reasoning frequently employed within MRTM clearly indicates how what appear to be small changes or deviations at the start of the mining value chain, can actually have significant effects on downstream processing performance (compounding effects) and the profitability of mining operations (Figure 2).

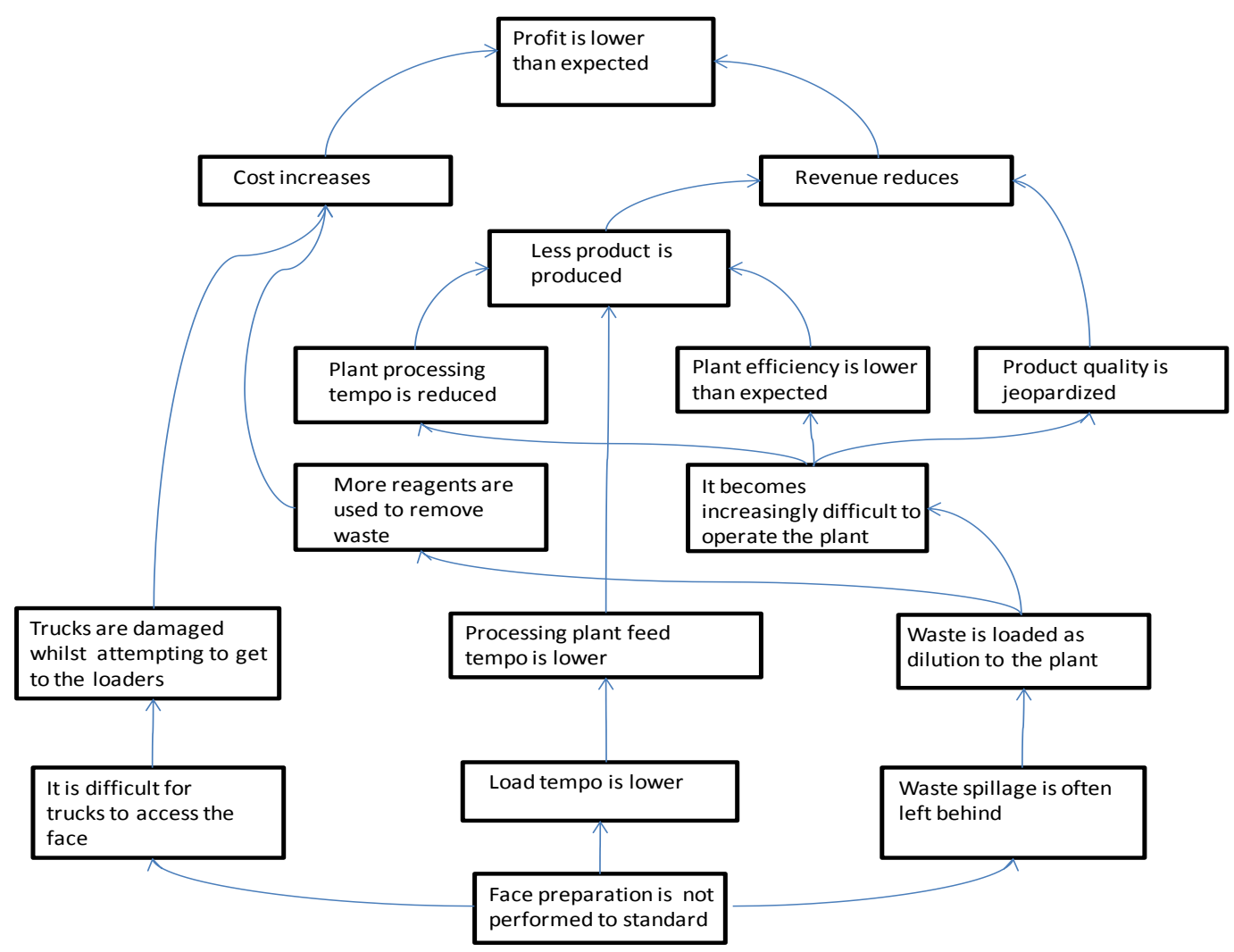

Figure 2: Cause-and-effect diagram illustrating the adverse effects that inadequate face preparation can have on the overall performance of an opencast mine

Figure 2 aims to indicate that a lack of proper face preparation can lead to lower production rates, lower process efficiencies, lower maintenance availability, increased cost and lower profitability. In fact, inadequate face preparation can render a mining system unstable and unpredictable.

It can be argued that the system behaviour shown in Figure 2 represents behaviour similar to what is presented in the Chaos Theory (Kellert, 1993). The latter states that small changes in initial conditions yield widely diverging outcomes to such an extent that it eliminates the ability to accurately predict the final outcome/performance of a system. In mining, as in any business, it is essential to accurately plan activities and forecast financial performance. Complex geological environments (variable initial conditions) can, however, render mining systems unpredictable due to the 'knock- on"/compounding effect it has on operational performance if not dealt with correctly and timeously.

\section{Defining MRTM}

In previous paragraphs the importance of the ability of a mining operations management methodology to effectively deal with the following key aspects was highlighted:

- variable geological environments (initial conditions)

- variable mining conditions

- variable raw material quality

- variable processing conditions

- moving bottlenecks

- changing mining supply chains

- the butterfly effect (chaos theory)

- combinations of the above 
In this paper, these issues are dealt with within a framework often used by operations management scholars when covering OM topics, namely Organisational Mindset and Culture, Organisational Structure, Business Strategy, Production Planning, Capacity Design and Management and Quality Management and Continuous Improvement.

\section{Organisational Mindset and Culture}

In general, mining organisations are either characterised by a mechanistic or organic/systemic mindset and culture with its associated behaviours as indicated earlier. Combinations of these two approaches also exist in more mature organisations
(McDonough and Leifer, 1983). Whereas typical OM practices and other broad-based management and improvement methodologies (TQM, SS and BPM) are based on a mechanistic mindset, MRTM is entirely organic/systemic in nature. Within the MRTM context it is believed that a systemic approach is required to exploit the full potential of the total mining system as alluded to earlier. This belief (Table 1) stems from the fact that it is the system and not individual parts in the system that produces the final product and the characteristics of the ore and ore body dictates downstream processing design and performance. A systemic flow-based approach is used to ensure that optimal performance is achieved.

Table 1: Beliefs associated with mechanistic and systemic mindsets in mining

\begin{tabular}{|c|c|c|}
\hline Mechanistic belief & Reasons why this belief is flawed & MRTM/systemic approach \\
\hline $\begin{array}{l}\text { 1. Mining systems are broken down into } \\
\text { departments and it is the contribution } \\
\text { of the different departments that yield } \\
\text { the final product. Costs and raw } \\
\text { material value are allocated per step as } \\
\text { the material moves through the system }\end{array}$ & $\begin{array}{l}\text { Only the final product produced is sold to } \\
\text { the customer and only when this happens } \\
\text { income will be generated }\end{array}$ & $\begin{array}{l}\text { The focus is on the rate at which income is } \\
\text { generated (maximum production rate and } \\
\text { optimal product payability) by the system as a } \\
\text { whole }\end{array}$ \\
\hline $\begin{array}{l}\text { 2. Raw material characteristics can be } \\
\text { blended to obtain an average blend } \\
\text { that would not destabilise downstream } \\
\text { processes }\end{array}$ & $\begin{array}{l}\text { Raw material characteristics such as } \\
\text { hardness, porosity, textural aspects, etc. } \\
\text { cannot be blended. E.g. a mixture of hard } \\
\text { and soft rock will not give a medium hard } \\
\text { rock blend }\end{array}$ & $\begin{array}{l}\text { Only material that behave similarly in } \\
\text { downstream processes (compatible material) is } \\
\text { blended. The physical flow and product } \\
\text { payability behaviour of the material in } \\
\text { downstream processes are considered }\end{array}$ \\
\hline $\begin{array}{l}\text { 3. The system capacity is equal to the } \\
\text { capacities of individual resources in a } \\
\text { system when the resource capacities } \\
\text { are balanced. Resources are allocated } \\
\text { on the basis of capacity required. }\end{array}$ & $\begin{array}{l}\text { Statistical variance in the performance of } \\
\text { individual resources and the dependency } \\
\text { between resources in a system cause the } \\
\text { system to operate below the balanced } \\
\text { capacity value }\end{array}$ & $\begin{array}{l}\text { The capacity of a system is equal to the capacity } \\
\text { of the capacity constraint resource (CCR). } \\
\text { Capacities are not balanced, but flow in the } \\
\text { system is balanced. Resources (people, } \\
\text { equipment, capital) are allocated based on flow } \\
\text { and product payability needs }\end{array}$ \\
\hline $\begin{array}{l}\text { 4. Fixing a broken/ underperforming part } \\
\text { in a system will improve the output of } \\
\text { the system linearly }\end{array}$ & $\begin{array}{l}\text { If the constraint in a system is not } \\
\text { established using flow and product } \\
\text { payability principles, the chances are good } \\
\text { that the performance of the constraint is not } \\
\text { improved and therefore the system } \\
\text { performance will not improve as expected }\end{array}$ & $\begin{array}{l}\text { Determine flow and product payability attrition } \\
\text { drivers. Attention is directed towards resolving } \\
\text { these issues. }\end{array}$ \\
\hline $\begin{array}{l}\text { 5. An equal focus on the different } \\
\text { parts/departments of a system will } \\
\text { ensure optimal performance of the } \\
\text { system as a whole }\end{array}$ & $\begin{array}{l}\text { The CCR determines the performance of a } \\
\text { system. Resources and time not directed } \\
\text { towards the CCR are wasted. This } \\
\text { approach also creates prioritisation } \\
\text { conflicts that negatively impact system } \\
\text { performance }\end{array}$ & $\begin{array}{l}\text { Focus is on the performance of the constraints, } \\
\text { PAY attrition drivers and the output of the } \\
\text { system as a whole. Synchronisation of the total } \\
\text { mining value chain (including raw material } \\
\text { needs) will ensure optimal performance }\end{array}$ \\
\hline $\begin{array}{l}\text { 6. An equal improvement focus on all } \\
\text { parts of the organisation will ensure } \\
\text { sustainable improvement }\end{array}$ & $\begin{array}{l}\text { This improvement approach over the long } \\
\text { term results in balancing of capacities, } \\
\text { which reduces a system's output over the } \\
\text { longer term }\end{array}$ & $\begin{array}{l}\text { Improvement initiatives focus on the } \\
\text { synchronisation of the total system. Specific } \\
\text { attention is given to the performance of the CCR } \\
\text { and limiting product payability attrition. } \\
\text { Elevation of system performance through } \\
\text { capital expenditure do not disturb the flow } \\
\text { balance and increase product payability attrition }\end{array}$ \\
\hline $\begin{array}{l}\text { 7. Averaged data will accurately } \\
\text { describe a complex environment }\end{array}$ & $\begin{array}{l}\text { Averaging data in a complex environment } \\
\text { hides the inherent complexity of the } \\
\text { environment (variability in data is not } \\
\text { evident) }\end{array}$ & $\begin{array}{l}\text { Only data from compatible environments (from } \\
\text { the same population) will be averaged. The data } \\
\text { always reflects the inherent complexity of the } \\
\text { relevant environments }\end{array}$ \\
\hline
\end{tabular}

From Table 1 it can probably be argued that a mechanistic mindset cannot serve complex mining environments effectively. In fact, it can cultivate behaviour that over the long term destabilises mining operations and renders it less predictable as discussed in ensuing paragraphs. MRTM on the other hand endeavours to establish a system throughput mindset and culture in a mining organisation. Furthermore, due to the high level of variability and overall complexity evident in many mining operations, MRTM also promotes the 
development of a change culture that supports people and operations to adapt to an ever-changing environment.

\section{Organisational Structure}

When a mechanistic mindset is employed, an organisation is typically structured according to well-defined sections/departments and managed through a hierarchical network as is evident in most mining organisations. It is claimed that these structures promote control, accountability, efficiency and specialist development. It also supports cost management and accounting practices (cost centres linked to specific departments). These structures serve simple and stable mining operations (little variability and a relatively small number of dependencies) reasonably well. Complex mining operations employing mechanistic structures however find it increasingly challenging to sustain and improve performance. A number of factors that can contribute towards this state are listed in Table 2.

Table 2: Factors that contribute towards poor performance of mechanistic structures in complex mining environments

\begin{tabular}{|c|c|c|}
\hline & Factor & Impact \\
\hline & $\begin{array}{l}\text { Organisations are broken up into its } \\
\text { different parts/departments }\end{array}$ & $\begin{array}{l}\text { 1. The focus is on the performance of the department instead of the performance of } \\
\text { the system as a whole, i.e. flow and product payability throughout the system } \\
\text { 2. Different functional entities (compared to one entity) could take longer to adapt to } \\
\text { change }\end{array}$ \\
\hline
\end{tabular}

2. Equal attention is given to all 1 . Organisations are staffed to perform optimally in all departments. This create parts/departments in the organisation bulky, expensive organisations and potentially distracts people from their work/goal of the company

2. Goals of different departments can be in conflict with one another, e.g. cost saving goals of a supply chain department can hamper production goals, e.g. if parts ordered are not of the required quality or take too long to be delivered

3. Improvement initiatives do not focus on the CCR and therefore in the best case waste money and in the worst case destabilise operations when capacities are balanced (i.e. when it is successful)

4. Cost saving exercises typically put the CCR under more pressure and the output of the system as a whole decreases

5. There is a focus on standardisation/best practices that could result in the implementation of practices/equipment/spares not fit for use in the environment where it is used (increase cost and lowers production)

6. An efficiency focus on equipment and activities across the organisation waste money at best and hampers the performance of the CCR at worst

\section{Hierarchical structures are used to manage mechanistic organisations \\ The decision-making and implementation processes take very long and do not support flexibility and adaptability}

MRTM on the other hand promotes organic structures developed from the theory of mechanistic and organic systems mentioned earlier. This theory originated from cell biology (Von Bertalanffy, 1972) and allows the comparison of large complex organisations with a living cell (systems theory). For survival, the cell adapts (handles unforeseen events, self-organises and finds new equilibrium) to new inputs. In mining, one can argue that organisations need to continuously adapt to changing inputs/initial conditions (complex ore/waste and ore body morphology as well as processing technology) and other external factors (labour productivity, legislative requirements and changing markets). Since most of the good quality ores and simple deposits have been nearly depleted and expectations are that the socioeconomic and legislative environments will only become more complex in future, it is possible that many mining operations will close their doors unless it can adapt (mindset and design) to an ever-changing environment.

Organic structures are, however, comparatively more complex and harder to establish. It is known to be flat, specialists and other services (HR, engineering, finances, etc.) are employed where they are most useful (no centralisation of specialists or services), decision-making is decentralised and services/equipment/ protocols are fit for use (limited standardisation and formalisation).

\section{Business Strategy}

Business strategy concerns itself with the survival of the business at the one end of the scale and adding value at the other. Both these concerns need to be focused on for a business to grow sustainably. The latter is possible when a business owns a full understanding of its environment, a strategy to optimally develop and allocate resources, a clear purpose and a strategy implementation process.

\section{Understand the environment}

No strategy can be successfully implemented if the environment within which it is implemented is not fully understood. From a MRTM perspective, understanding the flow and product payability behaviour of the raw material/ore is an essential part of not only the operations but also the strategic environment. It provides key information on how the raw material will actually behave throughout the processing chain (rate, quality, costs). Furthermore, information gathered from the mineral resources and reserves also reflect the complexity of the geological, mining and processing environments (variability in ore and waste 
morphology, ore body morphology, mining and processing thresholds) as it is condition based, i.e. geo-processing domains are developed which incorporates processing rates, recovery data, product quality details as well as cost information per domain. This approach renders mining performance more predictable and the strategy more executable.

A traditional/mechanistic approach, on the other hand, does not incorporate this information into its strategy. Instead it uses averaged volumes, grades (very often a "grade only" focus and not focussing on material behaviour through the mining value chain), capacities and costs (based on historical performance/best practices) as a basis for a strategy. In complex mining environments this approach confronts operations frequently with surprises and therefore a strategy that is difficult to implement.

\section{Resource development and allocation}

An organisation's resources (human, financial and operations) are generally regarded as the corner stone of the business' strategy. It provides the means through which value is generated and a competitive advantage is created and maintained. This is only possible if resources are correctly developed, allocated (prioritised) and exploited.

In complex mining environments a systemic flow-based approach towards the development and allocation of resources is preferred. The latter promotes developing resources for and allocating it to where it is needed most. Expending resources at the business' leverage points is likely to ensure that the output of the system as a whole increases. Furthermore, resources are allocated and prioritised based on the flow requirements of ore/materials, which in turn are affected by its environment (condition based) and not industry best practice or OEM (original equipment manufacturer) type norms and standards. When resources are developed and allocated based on mechanistic principles, the investment in many cases does not yield the desired results. This can be contributed to misdirecting it towards nonconstraints and the balancing of capacities in the system (instead of balancing flow) that can furthermore render these systems unstable.

When a flow and product payability view is taken of a mining operation, optimal results are obtained when all resources are synchronised. Synchronisation of a mining value chain endeavours to create stability and make system performance more predictable (must consider the physical flow and product payability behaviour of the material as well as the flow of cause-and-effect).

\section{Purpose of the organisation}

Most mining organisations currently contribute significantly towards the socio-economic well-being of the communities within which it operates. Its responsibility towards employees, customers (core concept of OM and TQM) and the natural environment has always been major concerns of mining organisations. These responsibilities can be dealt with in a more sustainable manner if the organisation is not only in a survival mode but also have the ability to add value over the longer term. Value adding in mining organisations is similar to most other organisations (organic growth, new markets, acquisitions, etc.). In addition to this, value adding in mining occurs by means of increasing the life-of-mine (LOM). This is achieved by minimising losses of the nonrenewable mineral resource during processing, i.e. increasing the mineable volume of ore or using less ROM material to produce the same amount or more product. In complex mining environments, a decrease in LOM can have a significant impact on a mining organisation's ability to add value.

MRTM addresses these losses as part of its physical flow and PAY dimensions. Apart from balancing flow and synchronising the entire mining value chain as mentioned earlier, losses are also tracked as material moves through the mining and processing environments. This information is used to calculate the return-on-reserve (ROR). The ROR considers the extractability and upgradeability of the raw material from a flow and product payability perspective (considers variability in initial conditions) and indicates the monetary value of metal extracted from a mining block or section at any stage of the process in relation to the monetary value of in-situ metal in a mining block or section excluding mining costs (Equation 1).

$$
\begin{aligned}
& R O R= \\
& \frac{\text { (Mass of metal in ore extracted } x \text { price of metal) }}{(\text { Total in-situ mass of metal in ore block } x \text { price of metal) }} \times 100
\end{aligned}
$$

A strategic approach towards improving the ROR (part of a reserve optimisation and LOM improvement strategy) of a mining organisation will not only add value at existing/new operations, it will also demonstrate the organisation's commitment towards responsible and sustainable extraction of a non-renewable natural resource. Another value adding concept promoted by MRTM is downstream integration (integration of smelters, refineries and mining operations). Downstream integration allows an opportunity to:

- Improve the system performance (up to the final product) compared to local optimisation that does not necessarily add value to the final product (lowers product payability)

- Extract maximum value from mineral reserves (improved downstream alignment and synchronisation)

- Improve overall system efficiency

- Lower risks associated with a sustainable supply of raw materials; the above-mentioned will not only result in optimal supply, it will also ensure a more consistent quality

- Further increase the LOM of the mining operation due to optimal utilisation of the mineral reserve

\section{Strategy implementation process}

Implementation of a strategy in complex mining environments can be a daunting task. A lack of system stability and predictability and operations finding themselves 
in a fire-fighting mode are not helping the cause. Furthermore, most big mining organisations have been in business for several decades and are mostly set in their ways. Implementing new paradigms will therefore be met with different levels of resistance at all levels in the organisation.

Two key enablers of MRTM, namely critical chain (Goldratt, 1997) and organisational change management (Cox Blackstone \& Schleier, 2003) are employed (within the context of complex mining environments) to ensure that objectives are achieved. The change process is very often the limiting factor in strategy implementation. If one considers that the establishment of a new paradigm requires a change in values and beliefs, followed by changes in behaviour, policies and structures, then the importance of effective change management as part of MRTM and the strategy implementation process cannot be over-emphasised. This change should also rather be viewed as an on-going process than a once-off exercise.

Finally, it is obvious that a strategy is not worth the paper it is written on if it cannot be implemented. In complex mining operations it is becoming increasingly difficult to be confident about the deliverables of a strategy due to an increase in the variability in initial conditions (internally the geological, mining and processing environments and externally the regulatory and market environments). MRTM mainly endeavours to stabilise (linking geo-processing variables and synchronising the total system) mining value chains to enhance the probability of successfully implementing the business strategy.

\section{Production planning}

Development of accurate and realistic production plans is a key focus area of operations management. Key inputs in a mine plan include the geological data from the geological model, engineering data from the physical asset management (PAM) model, mining rates and efficiencies from the mining model, processing details from the plant processing model and product details from the marketing model. HR and other resources are linked to each of these functions in the financial model. A comparison between how this data is generated and used in the respective models from traditional OM and MRTM perspectives is included in Table 3.

Table 3: Comparison between how data is generated and used within traditional OM and MRTM approaches

\begin{tabular}{|c|c|c|}
\hline Area & $\begin{array}{r}\text { Traditional OM approach } \\
\end{array}$ & MRTM approach \\
\hline Geology & 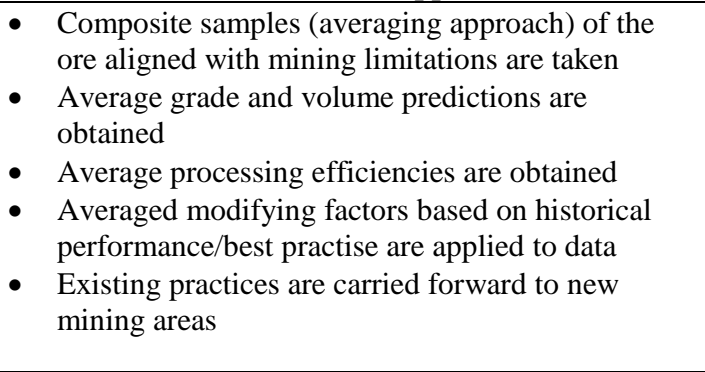 & $\begin{array}{l}\text { - Ore and waste are sampled based on the flow and } \\
\text { product payability behaviour of the material in } \\
\text { downstream processing } \\
\text { - Area specific (flow, PAY\& cost zones) norms called } \\
\text { condition driven standards (CDS) are obtained } \\
\text { - Area specific efficiencies are obtained (including } \\
\text { liberation effects, dilution effects, etc.) } \\
\text { A risk factor/indicator per area (flow, PAY\& cost } \\
\text { zones) is used as weighting factor (difficulty of } \\
\text { mining/processing indicator) }\end{array}$ \\
\hline $\begin{array}{l}\text { Mining, plant } \\
\text { processing, } \\
\text { Physical Asset } \\
\text { Management }\end{array}$ & $\begin{array}{l}\text { - Resource needs (equipment, consumables, labour) } \\
\text { are calculated based on the balancing of capacities, } \\
\text { incl. fixed ratios (best practices) } \\
\text { - Average load factors and extraction efficiencies are } \\
\text { used } \\
\text { - Fudge/modifying factors based on historical } \\
\text { data/best practise are applied to data }\end{array}$ & 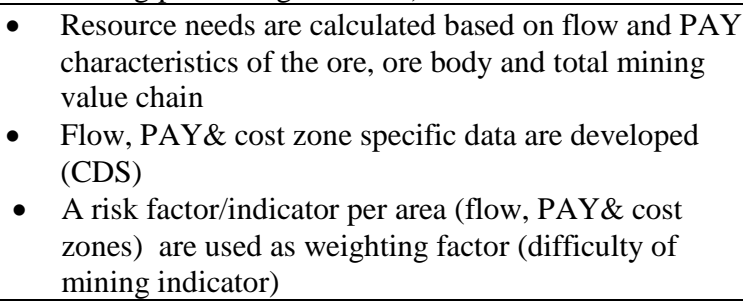 \\
\hline
\end{tabular}

In Table 3 it should be evident that MRTM emphasises the development of condition driven standards; norms and standards that are linked to specific geological and processing conditions. Techniques used in MRTM to generate and apply condition driven norms and standards (CDS) include ore body classification (into flow, PAY and cost zones) based on the physical flow and product payability behaviour of the ore and waste (Figure 3 ) and an operational performance matrix (Figure 4). 


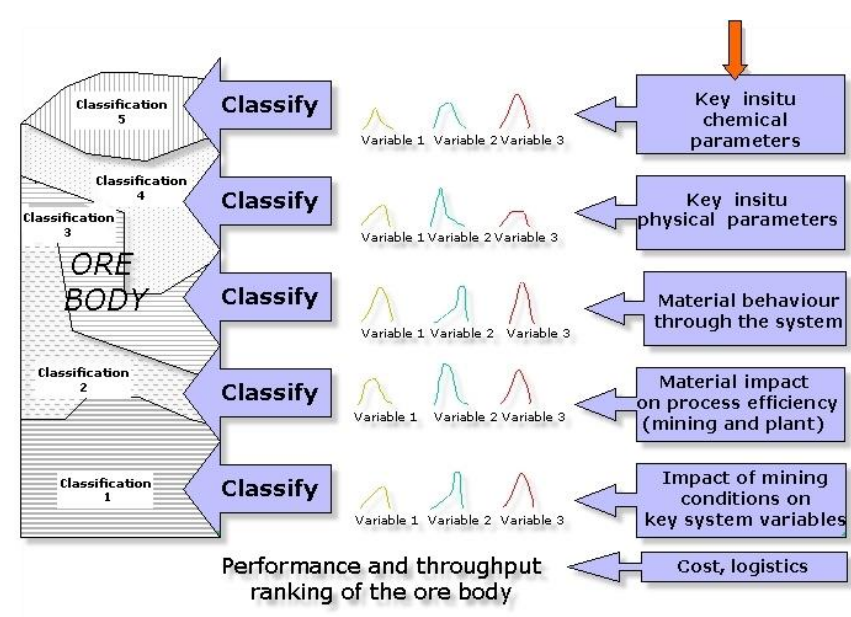

Figure 3: Factors considered in MRTM ranking and classification (domaining) of an ore body

During the ranking and classification (domaining) exercise the key flow, PAY and cost drivers are determined per domain and transferred to an operational performance matrix. In Figure 4 an operational performance matrix for an underground mine depicting the dip and depth below surface of the ore body as the key performance drivers, is shown.

\begin{tabular}{|l|c|c|c|c|l|}
\hline $\begin{array}{l}\text { Dip/Structure } \\
\text { Depthbelow } \\
\text { uurface }\end{array}$ & $<8^{\circ}$ & $8^{\circ}-12^{\circ}$ & $>12^{\circ}$ & $\begin{array}{c}\text { Fault/ } \\
\text { burnt }\end{array}$ & Dyke \\
\hline $0-200 \mathrm{~m}$ & 1 & 2 & 3 & 4 & 5 \\
\hline $200-300 \mathrm{~m}$ & 6 & 7 & 8 & 9 & 10 \\
\hline$>300 \mathrm{~m}$ & 11 & 12 & 13 & 14 & 15 \\
\hline
\end{tabular}

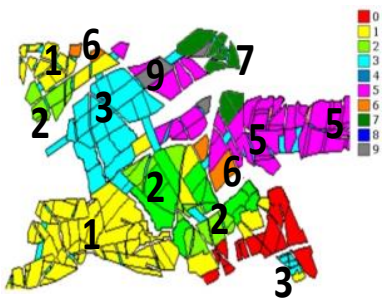

Figure 4: Operational performance matrix and the associated classified ore body

Each numbered block in the matrix holds the following information:

- In-situ grade and volume

- Expected ROM grade (include amount and quality of dilution/waste)

- Expected ROM volume

- Production rate (based on the constraint(s) in the mining system)

- Extraction efficiency

- Beneficiation efficiency (geometallurgical parameters)

- Processing cost (development, drilling, blasting, loading, hauling, processing)

The information in these blocks is transferred to the relevant mining blocks in the mining block model as inputs to the mine plan and scheduled similarly to what is encountered in geometallurgy practices (GeoMet, 2011). Compatible materials (materials behaving similarly in downstream processing) are also grouped together (can be blended prior to processing) where applicable during the classification exercise. By employing this approach, a plan that reflects the actual production, quality and cost details can be compiled with greater certainty. This approach also effectively deals with variable initial conditions as it considers the impact of variable flow, PAY and cost attributes in the mineral resource on the performance of the total mining value chain.

\section{Capacity design and management}

The traditional OM treatment of capacity design, selection and allocation often involves short-, medium- and long term concerns. Here factors such as facility design, technology selection and product strategy are, amongst other things, considered. Whilst MRTM recognises the need for a longer term capacity strategy, especially in greenfields environments, it similarly to the TOC approach, deals with short term capacity issues using the five TOC focussing steps where applicable (in highly unstable systems a different approach is required as discussed later). In this way the operations manager ensures that the system performance is optimal before considering capital expansions and the position (constraint) where capital will be spend is known.

Another important TOC and MRTM consideration in capacity design is the need for protective capacity at nonconstraint resources. This need stems from the view that protecting throughput is by far more important than inventory and operating expenses. Traditional OM and other broadbased management philosophies (TQM, SS, and BPM) promote systems where the production capacity is closely matched with the demand. This approach clearly limits operating expenses but results in the balancing of capacities throughout the value chain. The latter in turn leads to instability in the system due to statistical fluctuations in the performance of the different steps and difficulty to prioritise resource allocation between the steps (mining value chain steps).

As far as the management of capacity at a high level is concerned, MRTM recognises the existence of a large number of dependencies and inter-dependencies in complex systems (such as in complex mining environments). However, these systems can be simplified by only focusing on the areas that have a direct and immediate impact on the performance of the whole system (physical constraints, nonphysical constraints and PAY attrition drivers) as determined through cause-and-effect reasoning. The traditional OM approach does not contribute towards simplifying complex mining systems as it gives equal attention to all parts in the system (in line with quality management methodologies). Mining operations management of complex mining environments are therefore often characterised by a crisis/fire-fighting management approach. At an operational level TOC uses the concept of a logical product structure (LPS), which aids the tracking of product as it moves through the different processing steps. Traditional mining operations also often apply this concept by tracking the ore as it moves through the mining value chain. At a production level TOC employs the drum-buffer-rope (DBR) scheduling system, which is similar to traditional capacity requirements planning (Cox et al., 2003). Furthermore, buffer management supports 
the CCR in a similar manner than the input/output control functions used in traditional operations management practices.

In addition to these concepts, MRTM also deals with further complexity in mining systems (additional number of dependencies and interdependencies) caused by variability in the physical flow and product payability (quality) characteristics of the ore AND waste as the material moves through the mining value chain. Management of the mining value chain from a MRTM perspective therefore not only involves dealing with the physical and non-physical constraints and its dependencies referred to by TOC, but all the factors that influence the variability in physical and chemical (including mineralogical) characteristics of the raw materials. Factors such as the hardness, porosity, brittleness, texture, intergrowth, weathering effects, ultra fines, (ore morphology) different combinations of these factors and its variability directly impact the flow of material through the mining value chain and therefore the capacity of the system and the final product value.

The traditional/mechanistic approach towards dealing with the physical and chemical properties of ores involves specifying the correct size and number of equipment with its associated control systems (capacity based) to deal with an average raw material blend and some deleterious ore combinations (not all permutations are tested prior to specifying equipment and treatment processes). These tested blends and ore combinations are seldom seen in reality as variable amounts of ore and waste with variable characteristics are normally mined together due to variable ore and ore body morphology typical of complex mining environments. Equipment threshold limits are often exceeded whilst treating these blends, which in turn results in moving bottlenecks, variable product quality and an unstable/ unpredictable operating environment.

MRTM in turn recognises the capacity limitations of equipment (with its control systems) and mining processes. It therefore employs techniques that include ranking and classification of the ore body based on its flow, PAY and cost characteristics, the development of an operational performance matrix and scheduling of batches of compatible material to prevent occurrences where equipment and processes are required to operate outside its design threshold limits.

\section{Quality management and continuous improvement}

The concept of quality in processing environments has changed considerably during the twentieth century. Initially the focus was on quality inspections of finished goods. With inputs from several quality experts, including the work from Shewhart, Deming, Juran, Ishikawa and Crosby, it has evolved into a complete management philosophy (from quality control (QC) (Juran, 1999) to quality management (QM) (Shewhart, 1980) to total quality control (TQC) (Feigenbaum, 1991) to TQM) with a focus on process control, product development, process management, customer satisfaction and continuous improvement. It also laid the foundation for other (quality) management and continuous improvement methodologies including Six Sigma and BPM. However, the whole quality management and improvement movement drive was based on mechanistic thinking logic. It promotes quality improvement and reduction of variability throughout the organisation and departmental/local efficiency improvement, which as mentioned earlier lead to balancing of capacities and an unstable production environment. Many organisations applying this approach have failed to develop and sustain a competitive advantage (Fuchsberg, 1993; Simatupang \& White, 1998; Wilkonson, Redman \& Snape, 1995) and some have even referred to it as destructive (Hackman \& Wageman, 1995; Zbaracki, 1998) in nature.

Quality management and business improvement from a TOC perspective, however, emphasises a focus on quality and improvement where it is needed most, i.e. the area (physical or non-physical constraints) that causes quality/performance deviations through its five focusing steps. It also considers dependencies and interdependencies between resources and activities (flow of cause-and-effect) when prioritising quality management and improvement initiatives. Furthermore, within the TOC the focus remains on the goal of the organisation to make money now and in the future and all other necessary conditions are seen as thresholds that must simply be met.

In earlier paragraphs some shortcomings of the TOC with regards to handling raw material quality variation in the mining environment have been highlighted. MRTM through its product payability dimension addresses these shortcomings. This is achieved firstly by developing an indepth knowledge of the ore and ore body morphology (specific understanding of the impact it has on flow and product value), raw material changes during downstream processing, downstream processing technologies/processes and its limitations and synchronisation (systems thinking logic) of all of these elements with other resources required to produce the final product. Secondly, it assists mining operators through its tools and artefacts (questionnaire, process flow charts, cause-and-effect diagrams and process control charts) to identify the areas where product payability attrition occurs.

Lastly, MRTM utilises its ranking and classification process, operational performance matrix and scheduling of compatible ore blends to synchronise and stabilise mining operations and to enhance product payability (product value). It should be noted that blending of raw material is often practiced within MRTM to increase LOM and improve flow/product payability where possible. However, the emphasis is on preparing blends of compatible material and not blending materials at all cost. Intermediate process buffers are also approached on this basis. Rigorous quality control around these buffers is essential in mining as it can jeopardise the flow of material through the system and product payability if non-compatible materials are mixed on these stockpiles.

MRTM's ability to continuously improve mining organisations should also be considered. At a high level MRTM emphasises the importance to follow a systemic 
approach towards business optimisation. This includes amongst other things a focus on production leverage points, the balancing of flow (includes physical material flow) and PAY drivers that ensures system stability and predictability. At an operational level, MRTM recognises how difficult it is to identify the leverage point(s), areas where product attrition occur and areas where a lack in synchronisation exist in complex mining systems plagued by variability and instability and a lack of detail geological information that ignores the flow and product payability behaviour of the ore. It therefore deviates from TOC's five focussing steps to deal with the added complexity in a meaningful manner. The steps often used in MRTM (interventions are commodity and mine specific) include the following:

\section{Step 1: Identify potential focus and improvement areas}

This forms part of a high level screening exercise of the entire mining value chain. Checks often used include a comparison between planned and actual performance, finding correlations between plant feed quality and process efficiency, evaluating intermediate and final product volume and quality variance, looking at effective production time, and doing root cause analyses.

\section{Step 2: Define the system (primary value chain and associated cycles)}

The primary value chain and some (defined in step 1) of its associated cycles (e.g. planning cycle, mining development cycle, quality control cycle, spares delivery cycle, operator logistical cycle, etc.) are drawn out to generate an understanding of flow dependencies in the system.

\section{Step 3: Define variability in initial conditions}

Where deviations in planned vs actual performance for example exist, the impact of variable ore/ore body morphology or company policies/procedures on effective planning and mining need to be considered. The minimum and maximum levels of dilution and correction factors (fudge factors/production risk indicators) and its impact on system performance are quantified.

Step 4: Evaluate the system in terms of flow, product payability and decision-making logic

Data and information gathered in the previous steps are used to establish the current reality of the organisation (what to change?). A lot of emphasis is placed on the development of cause-and-effect diagrams (if....then relationships). A simulation programme is also utilised to evaluate findings. This is a critical step in the improvement process and findings must be shared with the relevant people from the mine to evaluate whether it reflects the reality.

\section{Step 5: Identify the resource with the least capacity and exploit it}

MRTM endeavours to simplify complex mining systems by establishing the capacity constrained resource (CCR - resource with the least capacity), the PAY attrition drivers and the associated necessary conditions. A simulation programme that incorporates all the relevant flow and product payability dependencies and inter-dependencies is used to assist with the identification and verification of the CCR for flow and the PAY attrition effects. Once the CCR is identified, its exploitation involves, amongst other things, optimisation of its available production time and inherent capability.

\section{Step 6: Develop and test synchronisation interventions}

Again cause-and-effect logic is employed to develop the future reality/solution (what to change to?) for the area/organisation under review. The simulation programme is used to test whether the proposed interventions will indeed improve the performance of the system as a whole. Furthermore, the change intervention required (how to cause the change?) to successfully implement the solution is considered.

\section{Step 7: Synchronise the system}

Synchronisation of the system entails the implementation of the proposed solutions that enhance flow, product payability and effective management/decision-making. Synchronisation of secondary value chains/cycles with the primary value chain activities, ore/concentrate characteristics with processing activities and reagent additions, all other resources and decision-making interventions (policies, procedures, protocols, etc.) need to be achieved.

\section{Step 8: Track the system performance}

A performance dashboard is established as part of the solution implementation. It reflects the key value drivers of the organisation and enables day-to-day measuring and management of performance. The establishment of performance measures and targets for operators and managers that drives the correct flow behaviour is an essential part of this step.

\section{Step 9: Elevate the system}

A strategic decision to increase the capacity of the CCR can result in a capital expansion of the system. Efforts to improve the output of the system are only directed towards the CCR or an area that influences the performance of the CCR directly.

\section{Step 10: Repeat the process}

Improvement is an on-going process. Any change in the position of the CCR due to capital expansion or unforeseen changes in the initial conditions of a mining organisation will require a repeat of the process or parts of the process.

Improvement methodologies have been criticised (Nave, 2002) for not addressing issues such as policies/protocols (formal and informal), management of change (including values), measurement of performance of managers and the 
general management approach (mechanistic vs systemic) of an organisation. With the ten step process discussed in pervious paragraphs, MRTM endeavours to address these and other obstacles to improvement in complex mining environments.

\section{Conclusions}

Research indicated that MRTM is largely based on the theory of mechanistic and organic systems, theory of constraints and chaos theory. As such, it is constructed to deal with the occurrence and effects of changes in initial conditions (internal and external environments), which cause instability and unpredictability in complex mining systems. The three dimensions of MRTM, namely physical flow, product payability and logical decision-making consider the implications of the above-mentioned theories. In doing so, MRTM addresses the shortcomings of traditional OM and TOC when applied in complex mining environments. It has been indicated that traditional OM practices and structures do not adequately serve complex mining systems as it is mainly based on mechanistic thinking logic. It also does not consider flow principles in its approach to mining management and improvement. In fact, there is good reason to belief that this approach exacerbates the complexity of complex mining systems over the long term as it results in balancing capacities instead of balancing flow.

MRTM also addresses shortcomings in the way TOC and other broad-based management and improvement methodologies handle raw material variability. These methodologies assume that raw material non-conformances are effectively dealt with upstream of the treatment process, i.e. no or only a few defective "parts" enter the processing flow line. In mining, however, all the raw material/ore inside the mining shell is processed. MRTM endeavours to address the variability caused by variable ore and ore body morphology (initial conditions) by ranking and classifying the ore body into specific flow, product payability and cost domains. This information is combined with the key throughput and product payability drivers in an operational performance matrix and used in planning, scheduling and economic evaluations (business scenarios). Furthermore, MRTM emphasises the importance of scheduling compatible ore types (material with similar flow and product payability behaviour in downstream processes) to the processing plants as a means to limit the effects of variability in initial conditions (flow constraints and product payability attrition). The above-mentioned steps contribute greatly towards synchronisation of the overall mining system. MRTM's approach towards continuous improvement was also highlighted. Many improvement methods have been criticised for not adequately dealing with issues such as company values, culture, the high level management approach (mechanistic vs systemic) and company policies/protocols. MRTM in turn views these aspects as prerequisites for change that must be considered and employs change management as one of its key enablers.
MRTM is therefore seen as a fit for use mining and improvement methodology that effectively deals with dependencies, interdependencies and variability in complex mining value chains through focusing on the variability in initial conditions (internal and external) and the synchronisation of the total mining system.

\section{References}

Burns, T. \& Stalker, G.M. 1961. The management of innovation. London, Tavistock.

CMR UCT [online] URL: http://www.cmr.uct.ac.za

Courtright, J.A., Fairhurst, G.T. \& Rogers, L.E. 1989. 'Interaction patterns in organic and mechanistic systems', Academy of Management Journal, 32(4): 773 - 802.

Cox, J.F., Blackstone, J.H. \& Schleier, J.G. 2003. Managing operations: A focus on excellence. Great Barrington, MA, North River Press.

Dahlgaard, J.J. \& Hahlgaard-Park, S.M. 2006. 'Lean production, six sigma quality, TQM and company culture', TQM Magazine, 18: 263 -281 .

Donaldson, L. 2001. The contingency theory of organizations. Thousand Oaks, Sage.

Eckes, G. 2001. The six sigma revolution. How General Electric and others turned process into profits. New York, John Wiley and Sons Inc.

Feigenbaum, A.V. 1991. Total quality control. 4th Edition. New York, McGraw-Hill.

Fuchsberg, G. 1993. 'Baldridge award may be losing some lustre', The Wall Street Journal. New York. April 19. B1.

GeoMet. 2011. Proceedings of the first AusIMM international geometallurgy conference 2011, 5-7 September 2011. Brisbane, AusIMM.

Goldratt, E.M. 1984. The goal. New York, North River Press.

Goldratt, E.M. 1997. Critical chain. Great Barrington, MA, North River Press.

Hackman, J.R. \& Wageman, R. 1995. 'Total quality management: Empirical, conceptual and practical issues', Administrative Science Quarterly, 40(2): 309 - 342.

Juran, J.M. 1999. Juran's quality handbook. 5th Edition. New York, McGraw-Hill.

Kellert, S.H. 1993. In the wake of chaos: Unpredictable order in dynamical systems. Chicago, University of Chicago Press.

McDonough, E.F III. \& Leifer, R. 1983. 'Using simultaneous structures to cope with uncertainty', Academy of Management Journal, 26(4): 727 - 735 .

Mine to Mill, 1998. Exploring the relationship between mining and mineral processing performance. Brisbane, AusIMM. 
Miningfeeds [online] URL: http://www.miningfeeds.com/ 2012/03/16/u-s-mining-industry-in-decline/

Nave, D. 2002. 'How to compare six sigma, lean and the theory of constraints', Quality Progress, March: $73-78$.

Scott, W.R. 2002. Organization: Natural and open systems. 5th Edition. Upper Saddle River, NJ, Prentice-Hall.

Shewhart, W.A. 1980. Economic control of quality of manufactured products $/ 50^{\text {th }}$ anniversary commemorative issue. New York, American Society of quality.

Simatupang, T. \& White, A. 1998. 'A policy resolution model for knowledge acquisition in quality management', Total Quality Management, 9(8): 767 - 779 .

Vom Brocke, J.H.K.V.J.H. \& Rosemann, M. 2010. Handbook on business process management: Strategic alignment, governance, people and culture. International handbooks on information systems, vol. 1. Berlin, Springer.

Von Bertalanffy, L. 1972. 'The history and status of general systems theory', Academy of Management Journal, 15(4): 407- 426.

Wilkonson, A., Redman, T. \& Snape, E. 1995. 'New patterns of quality management in the United Kingdom', Quality Management Journal, $37-49$.

Zbaracki, M.J. 1998. 'The rhetoric and reality of total quality management', Administrative Science Quarterly, 43(3): 602 - 636. 